\title{
Proposta de estimulación sensorial na contorna natural dun cativo con trastorno de espectro autista
}

\section{Sensory stimulation proposal in natural surroundings of one child with disorder of autistic spectrum}

Berta Fraga, Beatriz López

Asociación DISMACOR, Asociación DISMACOR

\begin{abstract}
Resumen
Os trastornos do espectro autista supoñen unha afectación nas competencias sociais, comunicativas e lingüísticas que provocan alteracións tanto psicolóxicas como condutuais na persoa. Na maioría dos casos existe unha desorde sensorial que se palpa na incapacidade para desenrolar actividades cotiás e para conxugar os diferentes estímulos que reciben do medio elaborando respostas axeitadas e adaptadas. No presente traballo recollemos unha proposta de intervención en contorna natural cuxo principal obxectivo é a estimulación multisensorial dun cativo de seis anos con múltiples dificultades para a integración perceptiva, que se concretan en problemas psicomotores, falta de autonomía e dificultades de adaptación ao medio.

Palabras clave: Trastornos de espectro autista, desorde sensorial, integración sensorial, intervención en contornas naturais.
\end{abstract}

\section{Abstract}

Disorder of autistic spectrum suppose an affectation in social, communicative and linguistics skills which cause affectation both psychological and conductual on the person. Mayoralty there is a sensorial disorder which are shown in their incapacity for dealing with daily activities and for mixing different stimulus they kept making correct and adapted answers. The present assessment shows an intervention proposal in natural surroundings where the principal objective is multisensorial stimulation of a child of six years old with a lot of difficulties for perceptive integration, which are shown in psychomotor problems, lack of autonomy an adapt difficulties.

Keywords disorder of austistic spectrum, sensorial disorder, sensorial integration, natural surroundings intervention.

\section{Introdución}

O autismo é un trastorno do neurodesenvolvemento que ten a súa orixe nas idades temperás, e que se concreta na presenza de alteracións que afectan, primordialmente, a tres aspectos (Idiazábal-Áletxa e Boque-Hermida, 2007): déficits na interacción social, dificultades no desenvolvemento lingüístico e patróns de conduta e intereses moi restrinxidos (DSM V).

Déficits nas relación sociais e na interacción con outras persoas

Os nenos con autismo manifestan dificultades no mantemento de contacto ocular e as aproximacións ás demais persoas, problemas para comprender as emocións dos demais e empregalas para poder dar resposta ás mesmas, déficits para participar en conversas e utilizar as fórmulas de relación axeitadas para poder manter unhas relacións correctas cos que lles rodean. Estas dificultades tamén se palpan en problemas para o bo desenvolvemento da comunicación non verbal (linguaxe corporal, utilización de xestos ...).

Estas limitacións provocan nos nenos, normalmente, problemas para relacionarse cos seus iguais ao non ser quen de comprender ditas relacións e axustar o seu comportamento aos continuos cambios que ocorren nas mesmas.

\section{Afectación no desenvolvemento lingüístico}

O desenvolvemento dos nenos con autismo soe proseguir uns patróns normais ata os 18 meses (Buceta, 2011), momento no cal tanto os familiares como os profesionais refiren o comezo da perda de habilidades adquiridas e a aparición de comportamentos estraños, problemas que van restrinxindo a adaptación do pequeno ao mundo que lle rodea.

Os déficits e o funcionamento dos nenos con autismo varía considerablemente dun individuo a outro, pero un aspecto que soen ter en común todos eles son as dificultades no inicio da fala, os nenos con autismo presentan un retraso na aparición da linguaxe verbal (Rodríguez-Barrionuevo e Rodríguez-Vives, 2002), aínda que moitos deles chegan a acadar un nivel de competencias verbais que lles permiten comunicarse sen problemas.

Patróns de conduta, intereses ou actividades restritivas e repetitivas.

É frecuente nos nenos con autismo que presenten movementos ou fala estereotipada e repetitiva (saltos, xirar obxectos, alinealos, ecolalias ...) que soen emparellarse aos momentos de maior excitación emocional do neno.

Outro aspecto do que se derivan constantes problemas para adaptarse ao mundo que lles rodea e a súa 
inflexibilidade que se manifesta na imposibilidade de aceptar cambios nas súas rutinas, presenza de rituais e a existencia de intereses moi restrinxidos.

Un aspecto moi importante dentro deste bloque sintomatolóxico é a hipersensibilidade sensorial que soe manifestarse na presenza dun elevado nivel de tolerancia á dor, hiperreactividade a sons e texturas, fixación por analizar os estímulos dun xeito peculiar (lambelos, ulilos ...) e un interese agudizado por determinados patróns estimulares (como poden ser luces ou obxectos en movemento). Precisamente, esta característica postúlase como un dos primeiros síntomas que poden preceder ao diagnóstico de Autismo (Imperatore e Reinoso, 2007).

De acordo coa teoría da integración sensorial, este trastorno do procesamento sensorial supón unha afectación que modifica a capacidade de experimentación das sensacións a nivel multisensorial (vista, son, tacto, olfacto, gusto e motricidade) (Ayres, 1972) e impide a organización das mesmas para elaborar condutas adaptativas e aprendizaxes. Os órganos sensoriais encárganse de captar pequenos fragmentos de información estimular que deberán integrarse para que se convertan en elementos significativos; para iso, diferentes estruturas cerebrais conflúen a súa actividade localizando, clasificando e organizando eses inputs sensoriais (Cuesta, 2008).

O centro cerebral encargado de combinar a información sensorial, emocional e cognitiva é a cortiza insular, lugar que se atopa afectado en diferentes trastornos psicolóxicos, e tamén no Autismo. Neste sentido, recentes investigacións atoparon dificultades na cortiza insular para poder combinar estímulos sensoriais en ratos con autismo inducido, ademais de atopar un funcionamento semellante ao esperado para as crías; o que manifesta unha inmadurez de certas áreas cerebrais e unha hiperreactividade ante a presenza simultánea de estímulos que acceden á persoa por diferentes vías (Gogolla, Takesian, Feng, Fagiolini e Hensch, 2014).

As dificultades de integración estimular nos nenos con autismo concrétanse en problemas para modular a entrada e o rexistro de sensacións (obsérvase sempre un mellor funcionamento a nivel visual que en outra calquera modalidade sensorial); fallas na combinación da integración de ditas sensacións e, por consiguiente, déficits na planificación da acción (Fandos, 2013). En resumo, os nenos con autismo son capaces de procesar estímulos físicos sinxelos; pero son incapaces de codificar e interpretar estímulos sensoriais máis complexos (Comin, 2015) para elaborar respostas axeitadas e adaptadas ao medio.

\section{Método}

\section{Participantes}

O suxeito protagonista desta proposta é un neno de seis anos diagnosticado de trastorno de espectro autista dende os dous anos. Actualmente cursa primeiro de educación primaria nun centro ordinario con apoio de audición e linguaxe e reforzo escolar. Paralelamente recibe intervención psicolóxica a domicilio pola nosa asociación.
Dende o comezo das nosas intervencións acusáronse importantes problemas para a correcta integración sensorial o que lle ocasionaban ao neno: baixa comprensión do entorno que lle rodea, falta de autonomía persoal, presenza de estereotipias e posturas estrañas, hipersensibilidade aos sons, problemas psicomotores, hipersensibilidade ao contacto, alto umbral de tolerancia á dor e baixo coñecemento e comprensión do seu propio corpo.

\section{Obxectivos}

O obxectivo principal da proposta de estimulación sensorial é dotar ao neno dunha boa capacidade de adaptación e resposta ao medio, de cara a mellorar a súa calidade de vida e a súa relación coa contorna e cos que lle rodean.

Mellorar o control psicomotor fino.

- Corrixir a postura corporal.

- Mellorar a capacidade de imitación.

- Aprender a clasificar os estímulos e atopar as características comúns entre eles.

- $\quad$ Responder preguntas sinxelas sobre realidades novas e coñecidas.

- Reducir as condutas disrutivas asociadas a momentos de frustración e enfado e substitución destas por verbalizacións e respostas máis adaptativas.

- Vestirse e desvestirse só, comer só e axudar a poñer a mesa, e axudar no seu propio aseo.

- Comezar a controlar esfínteres e aprender a secuencia do uso do baño.

- Reducir a inquietude motora.

- Aumentar a tolerancia a texturas novas.

\section{Procedemento}

Unha vez concretados coa familia aqueles aspectos que se debían traballar para que o neno acadase un funcionamento máis adaptativo, púxose en marcha un programa de intervención completamente personalizado que ten como liña metodolóxica principal o aproveitamento das propias características da contorna natural do neno de cara a potencializar o seu desenvolvemento e conseguir unha maior xeralización do resultados obtidos. Ademais, cóntase coa participación activa e guiada dos seus familiares máis próximos e trabállase para adaptar o propio medio do neno co fin de facilitarlle apoios que lle axuden a comprendelo e interpretalo, así como a elaborar as respostas máis axeitadas en cada momento.

De cara a mellorar a calidade de vida do pequeno, establecéronse os seguintes obxectivos e liñas de intervención: mellorar a súa propiocepción e aumento da tolerancia á estimulación, melloría da capacidade psicomotora grosa e fina e aumento da autonomía persoal.

O coñecemento do neno mostrounos a existencia de diferentes partes do corpo cuxa identificación non estaba completamente adquirida. O fin é conseguir que o neno sexa quen de detectar aqueles aspectos que lle incomodan e poida empregar todas as partes do seu corpo de cara a emitir respostas e desenvolverse no 
medio, aprendendo a identificar as súas características e límites. En concreto o neno presenta problemas para o contacto das extremidades inferiores. Durante o traballo co pequeno atopáronse condutas desadaptativas asociadas a esta dificultade de identificación: o neno anda sobre as puntas, non permite que se lle corten as unllas e non protesta cando ten feridas nos pés.

Para reducir a hipersensibilidade ao contacto dos pés utilízanse diferentes materiais que xogan coa presentación de múltiples texturas que vaian estimulando de diferentes xeitos aquelas partes do corpo que o neno non identifica correctamente. A realización destes procedementos lévase a cabo en diferentes momentos e contextos (na ducha, mediante xogos, no parque, na praia ...) e ínstase aos pais a que traballen esta estimulación en todos aqueles ambientes onde se desenvolva o neno.

O neno ten asociado o proceso de cortar as unllas con momentos de ansiedade e dor; por iso vanse emparellando este proceso con consecuencias atractivas para el. Utilizando sempre apoio visual onde se relata a secuencia que se vai seguindo e o reforzo que conseguirá unido a unha aproximación sucesiva ao estímulo aversivo: primeiro conséguese que o neno acepte ter cerca as tesoiras, despois que as colla e pouco a pouco que o neno vaia aceptando o corte propiamente. Así mesmo, dótaselle do material necesario para que o neno poida manifestar os seus sentimentos mentres se realiza o progreso (en concreto elementos visuais e verbais que resuman as súas emocións e que nos axuden a comprender como vai percibindo o neno a experiencia).

A hipersensibilidade dunhas partes do corpo unido a hiposensibilidade asociadas a outras leva ao neno a presentar posturas incorrectas e estereotipias (andar de puntas, beliscar as mans, aleteos ...). Está demostrado que moitos destes movementos e autolesións derivan da falta de coñecemento dos nenos do seu propio corpo e realízannas para precisar os seus propios límites e ser quen de separar o seu propio ser da contorna que lle rodea. Para reducir estes movementos estereotipados otórganselle ao neno alternativas de comportamento que vanse repetindo co fin de substituílos por outras formas condutuais máis adaptativas mediante a melloría das capacidades psicomotoras.

De cara a conseguir unha mellor competencia psicomotora ponse en marcha unha serie de actividades que permiten tanto a estimulación dos diferentes grupos musculares como a integración e o movemento coordinado deles para conseguir emitir respostas axeitadas (realizar labirintos, superar pequenos obstáculos, aprender coreografías ...).

O mellor autocoñecemento de todo o seu corpo axúdalle a identificar como é o seu propio funcionamento e vaille permitindo aumentar a súa autonomía persoal (o que redunda, nun aumento da súa calidade de vida). Os principais fitos autónomos que se traballaron foron o control de esfínteres, vestirse e desvestirse, bañarse e ducharse. Para todas as competencias estableceuse nun programa de reforzos visuais e materiais que ían precisando aqueles comportamentos que desexábamos que o neno fora adquirindo. Ao igual que coa redución da ansiedade asociada a problemas de coidado persoal, utilizouse a aproximación sucesiva cara ó éxito para ir precisando o correcto funcionamento do pequeno.

Así mesmo, utilízanse aos pais como modelo para que vaia aprendendo as condutas de autonomía que se requiren. Nun primeiro momento realízase un moldeamento guiando fisicamente ao neno mentres se ducha, se viste, ... posteriormente vaise substituíndo esta guía por apoios visuais e simbólicos que indiquen os movementos e as pautas que deberá ir realizando.

Paralelamente desenvólvese un programa de relaxación onde participan tanto os pais como o neno e onde se busca reforzar o vínculo paternofilial así como axudarlle ao neno a canalizar os seus impulsos (que moitas veces se derivan de falta de comprensión da contorna natural onde se desenvolve). Tamén nestas sesións búscase a estimulación sensorial do neno xogando coa olor, o tacto, o son ... dos propios corpos dos pais; precisando, así, as diferenciacións entre os límites do pequeno e os dos seus familiares.

\section{Resultados e conclusións}

De cara a plasmar os avances elabórase unha táboa onde se recolle o funcionamento previo do neno e o actual, referente aos obxectivos plantexados:

\begin{tabular}{|c|c|}
\hline $\begin{array}{l}\text { Funcionamento anterior á } \\
\text { implantación do programa }\end{array}$ & $\begin{array}{l}\text { Funcionamento actual } \\
\text { (despois dun ano de } \\
\text { participación no } \\
\text { programa) }\end{array}$ \\
\hline $\begin{array}{l}\text { O neno non era quen de } \\
\text { soportar certas texturas, } \\
\text { alimentos, olores ... }\end{array}$ & $\begin{array}{l}\text { Actualmente os límites de } \\
\text { sensibilidade do neno } \\
\text { están acadando uns niveis } \\
\text { de tolerancia moito } \\
\text { maiores e o neno xa é } \\
\text { quen de identificar } \\
\text { aquelas partes do corpo } \\
\text { onde presenta molestias, } \\
\text { diminuíndo o seu umbral } \\
\text { da dor. }\end{array}$ \\
\hline $\begin{array}{l}\text { O neno presentaba } \\
\text { numerosas estereotipias } \\
\text { non funcionais que } \\
\text { implicaban graves } \\
\text { problemas de } \\
\text { concentración. }\end{array}$ & $\begin{array}{l}\text { Unha melloría no } \\
\text { concepto sobre os seus } \\
\text { límites e potencialidades } \\
\text { están mellorando a súa } \\
\text { postura corporal e xa é } \\
\text { quen de controlar } \\
\text { algunhas das condutas } \\
\text { estereotipadas, dándoselle } \\
\text { a si mesmo reforzo verbal } \\
\text { e substituíndo ditas } \\
\text { respostas por movementos } \\
\text { máis adaptativos. }\end{array}$ \\
\hline $\begin{array}{l}\text { O neno non era quen de } \\
\text { vestirse só nin desvestirse. }\end{array}$ & $\begin{array}{l}\text { Nestes momentos o neno } \\
\text { vístese e desvístese só co } \\
\text { apio visual da acción. } \\
\text { Durante a ducha o neno é } \\
\text { quen de lavarse e }\end{array}$ \\
\hline
\end{tabular}




\begin{tabular}{|l|l|}
\hline seu baño. & $\begin{array}{l}\text { enxugarse sen axuda. } \\
\text { Polo que se refire á } \\
\text { O neno non come sen } \\
\text { axuda. }\end{array}$ \\
$\begin{array}{l}\text { comida o neno xa axuda a } \\
\text { poñer a mesa (comezando } \\
\text { a ser consciente daqueles } \\
\text { elementos que faltan) e } \\
\text { como sen axuda, } \\
\text { indicando verbalmente } \\
\text { cando quere rematar e } \\
\text { axudando a recoller os } \\
\text { seus desperdicios. }\end{array}$ \\
\hline
\end{tabular}

Tabla 1.: Resultados obtidos

Os resultados mostran unha mellor adaptación do pequeno á súa contorna unha diminución das condutas disrutivas, un maior uso da explicación verbal para mostrar os seus sentimentos e desexos, maior tolerancia aos cambios e un aumento da autonomía persoal. En si, todos estes avances permiten que o neno vaia mellorando a súa autonomía e diminúan as rabietas asociadas a momentos de confusión e falta de comprensión do complexo estimular que se lle presenta na súa vida cotiá.

\section{Referencias}

Ayres, A. J. (1972). Sensory Integration and Learning Disorders. Los Angeles, CA: Western Psychological.

Buceta, M.J. (2011). Manual de Atención Temprana. Madrid: Editorial Síntesis S.A.

Comin, D. (2015). Abordaje del Trastorno Sensorial en el Autismo [Mensaje en un blog]. Recuperado de http://autismodiario.org/2015/01/15/abordaje-deltrastorno-sensorial-en-el-autismo/

Cuesta, A. (2008). Integración Social [Mensaje en un blog]. Recuperado de http://www.agapasm.com.br/Artigos/Integracion\%20s ensorial.pdf

DSM V

Fandos de Paglia, H. Déficit De La Integracion Sensorial En El Trastorno Del Espectro Autista [Mensaje en un blog]. Recuperado de http://didacticaenautismo.blogspot.com.es/2013/09 /deficit-de-la-integracion-sensorial-en.html

Gogolla, N., Takesian, A.E., Feng, G., Fagiolini, M. e Hensch, T.K.. (2014). Sensory Integration in Mouse Insular Cortex Reflects GABA Circuit Maturation Neuron. Neuron , Recuperado de: http:// dx.doi.org/10.1016/j.neuron.2014.06.033

Idiazábal-Aletxa e Boque-Hermida, E. (2007). Procesamiento Cognitivo en los Trastornos del Espectro Autista. Neurol 44 (2).

Imperatore, B. e Reinoso, G. (2007). Revisión de la Literatura: Déficit de Procesamiento Sensorial en el Espectro del Autismo. Revista Chilena de Terapia Ocupacional, 7.

Rodríguez-Barrionuevo e Rodríguez-Vives, M.A. (2002). Diagnóstico Clínico del Autismo. Neurol, 34 (1). 